\title{
CUARENTA AÑOS DE LEYES DE COSTAS EN ESPAÑA (1969-2009)
}

\author{
Francisco José Torres Alfosea \\ Instituto Interuniversitario de Geografía \\ Universidad de Alicante (España)
}

\section{RESUMEN}

La ley española 22/1988, de Costas, que supera ya los veinte años de vigencia, se propuso como el instrumento definitivo que permitiría recuperar estos espacios para el uso ciudadano, eliminando la propiedad privada en el dominio público y garantizando su recuperación. Sin embargo, transcurridas dos décadas desde su aprobación, y cuatro desde la entrada en vigor de la Ley de Costas de 1969, el balance no es positivo. España sigue padeciendo una ocupación indiscriminada de sus costas, especialmente en la fachada mediterránea, que revela la falta de una verdadera política integrada del litoral. Se actúa de forma puntual sobre estos lugares, mientras la gran complejidad técnica y jurídica para la aplicación de la ley ha provocado numerosos problemas de tipo técnico, social y económico, vinculados a los deslindes, expropiaciones y demoliciones anunciados. Este artículo pretende ofrecer una perspectiva de conjunto de la normativa sobre costas en España, un análisis crítico - desde la geografía- del texto jurídico y un balance de las consecuencias de estos cuarenta años de aplicación.

Palabras clave: ley de costas, costas, litoral, deslinde, dominio público marítimo-terrestre, España, ley 22/1988, informe Auken.

\begin{abstract}
Spanish coastal law 22/1988, which overcomes already twenty years of force, was proposed as the definitive instrument that would allow to recover these spaces for the civil use, eliminating the property deprived in the public domain and guaranteeing its recovery. Nevertheless, passed two decades and four from the entry into force of the coastal law from 1969, the balance is not positive.
\end{abstract}


Spain continues suffering an indiscriminate occupation of his coasts, specially in the Mediterranean front, which reveals the lack of a real integrated coastal policy. It is operated of punctual form on these places, while the technical and juridical complexity of the application of the law has generated the appearance of many technical, social and economic problems, linked to the demarcation, expropriations and demolitions announced. This work tries to offer a global perspective of the coastal regulation in Spain, a critical analysis -from the geography- of the juridical text and a balance of the consequences of these forty years of application.

Key words: coastal act, coasts, public domanin demarcation, Spanish coasts, 22/1988 law, Auken Report.

\section{LA LEY DE COSTAS DE 1969}

Puede afirmarse que la planificación del litoral no ha estado nunca entre las prioridades de la Administración española, incluso a pesar de que se cuente con disposiciones reguladoras específicas de este espacio desde hace cuarenta años.

En efecto, en España se aprueba la primera Ley de Costas en abril de 1969. Hasta esa fecha, la regulación del espacio tierra-mar dependía de leyes de puertos (de 1880 y 1928), cuyo objetivo fundamental era atender las necesidades de navegación y condiciones de abrigo para las embarcaciones, dejando lógicamente al margen el espacio costero no portuario. De hecho, en la primera de ellas, la ley de Puertos de 1880, se anula una servidumbre de vigilancia y salvamento de 20 metros que se establecía en la Ley de Aguas de 1866, y que podemos considerar -indirectamente- como la primera franja de protección de tan sensible espacio. En estos años finales del siglo XIX y primera mitad del $\mathrm{XX}$, en cualquier caso, las presiones sobre el espacio litoral eran muy limitadas y no justificaban un cuerpo normativo específico que regulara las actividades ni las intensidades de uso, ni podemos considerar el litoral como un espacio amenazado.

La aprobación de la Ley de Costas de 1969, sin embargo, se produce en un contexto económico y social notablemente distinto. La apuesta decidida del régimen franquista por el turismo como forma de obtener los ingresos necesarios para equilibrar la balanza de pagos era evidente ya desde $1963^{1}$. España precisaba las divisas procedentes del turismo, y la corta visión de la dictadura interpretó el paisaje litoral como el espacio a consumir para lograrlo. El respe-

1 Ley 197/1963, de Centros y Zonas de Interés Turístico Nacional. Su artículo 1 decía, textualmente: «Es objeto de la presente Ley la ordenación turística del territorio nacional por medio de la planificación y desarrollo de Centros y Zonas de Interés Turístico». 
to a la propiedad privada prevalecía expresamente sobre la preservación de los ecosistemas o la estabilidad de la línea de costa. Todas las actuaciones debían quedar supeditadas a la miope interpretación de que el crecimiento inmobiliario y la atracción de turistas significaría, necesariamente, desarrollo en términos globales. Y, aunque es innegable que la aportación de estas actividades dinamizó la economía, generó empleo y contribuyó a elevar el nivel de vida de los españoles, no es menos cierto que se hizo a costa de la privatización de su territorio más sensible, el litoral.

Para ello, baste citar tres ilustrativos ejemplos, que permiten comprender las líneas básicas de la política costera durante los casi veinte años en que la Ley de costas de 1969 estuvo en vigor:

- La norma enumeraba tan sólo tres bienes como pertenecientes al dominio público marítimo-terrestre: las playas (aunque dependiendo de la vegetación que tuvieran), la zona marítimo terrestre (incongruentemente delimitada por las olas en los mayores temporales ordinarios) y el mar territorial, incluyendo en este último los recursos que en él sean aprovechables ${ }^{2}$. Además de la parquedad en la enumeración, sorprende el consentimiento expreso de la presencia de propiedad privada enclavada en cualquiera de estos bienes, presencia que queda garantizada desde el momento en el que éstos se clasifican como de dominio público «sin perjuicio de los derechos legalmente adquiridos» (art. 1).

- La ley de costas de 1969 establecía, además, que los terrenos ganados al mar como consecuencia directa o indirecta de obras serían propiedad de quienes las hubieran llevado a cabo (art. 5.3). Basándose en esta disposición, numerosos enclaves costeros españoles en superficie ganada al mar pasaron a ser de propiedad privada y, por tanto, ajenos a la regulación de la ley de costas de 1969.

- El reglamento que desarrolla la ley de costas de 1969 no se aprueba hasta 1980, once años después. Sin el reglamento, algunas disposiciones legales resultan inaplicables, especialmente las que precisan de un desarrollo para su puesta en práctica, como, por ejemplo, la que debe especificar las dimensiones y frecuencia de la servidumbre de paso, que permita acceder desde tierra a la costa. Se evidencia así una clara falta de voluntad política, en un momento en el que la tramitación de una ley no dependía más que de la voluntad del Jefe del Estado.

2 La inclusión del Mar Territorial acata lo dispuesto en la I Convención de las Naciones Unidas sobre Derecho del Mar (Ginebra, 1958), en la que se firman cuatro protocolos: sobre el Mar Territorial, la Plataforma Continental, Alta Mar, y otro sobre Pesca y Conservación. Sólo el primero de ellos contó con respaldo suficiente y fue aprobado en esa fecha. 


\section{LAS COSTAS EN LA CONSTITUCIÓN ESPAÑOLA DE 1978}

Puede entenderse, en el contexto socio-económico del momento, que la protección costera no estuviera entre las prioridades de la Administración, e incluso puede llegarse a entender que, aunque evidentes, los perjuicios al entorno litoral se consideraran asumibles a la vista del beneficio a corto y medio plazo generado. Sin embargo, más allá de esta perspectiva miope, el principal problema con el que se enfrentará la Administración democrática posterior, emanada de la Constitución de 1978, será la consolidación de los derechos adquiridos por particulares a raíz de la ley de 1969, en espacios que, por su propia naturaleza, deberían ser considerados, sin excepción, como integrantes del dominio público marítimo-terrestre, y, por tanto, de soberanía nacional y uso público.

La Constitución Española, aprobada en referéndum nacional el 6 de diciembre de 1978, así los consagra, estableciendo, en su artículo 132.2, que «Son bienes de dominio público estatal los que determine la Ley y, en todo caso, la zona marítimo-terrestre, las playas, el mar territorial, y los recursos naturales de la zona económica [exclusiva] y la plataforma continental». La inclusión expresa de estos espacios en el dominio público ${ }^{3}$, y muy particularmente de las playas, deja en evidencia el ánimo de limitar la presencia de propiedad privada en ellos, hasta este momento consentida expresamente, que deberá ser objeto, como dice el propio artículo de la Constitución, de un desarrollo legal específico, que no llegará hasta diez años después, cuando se apruebe en las Cortes Españolas el actual texto legal de referencia en el litoral español, la ley 22 /1988, de Costas.

Conviene indicar que la redacción del artículo constitucional dista mucho de ser precisa. No sólo porque a la zona económica exclusiva se le suprime el segundo término (a pesar de que estaba regulada desde el 20 febrero de ese año, con la ley 15/1978), sino porque parece considerar como de dominio público a toda la plataforma continental, cuando esta cualidad recae sólo sobre los recursos (vivos y no vivos) que se encuentren en ella. Así, ni el lecho, ni la columna de agua, ni el espacio aéreo situado sobre la plataforma continental son bienes de soberanía nacional y uso público, sino sólo aquellos elementos que, encontrados en ella, sean susceptibles de aprovechamiento económico (bancos de pesca, recursos minerales, fuentes de energía...).

3 Los bienes enunciados en la Constitución forman parte del dominio público por su naturaleza, a diferencia de los que se incorporen con la nueva ley, en 1988, que lo serán por determinación legal. No hay diferencias en la protección de ambos, pero el hecho de figurar entre los primeros implica que cualquier otro texto legal futuro sobre costas deberá mantenerlos dentro del demanio, salvo modificación constitucional, y, por tanto, su protección debe inspirar cualquier norma legal. 


\subsection{Los años ochenta: un nuevo escenario exterior e interior}

Si la Ley de costas de 1969 se aprueba en un contexto social y económico hasta entonces desconocido, puede afirmarse algo similar del momento en el que la nueva -y actual- ley de Costas ve la luz. En 1986, Francia aprueba la ley 86-2, de 3 de enero, relative à l'aménagement, la protection et la mise en valeur du littoral. Dicha loi littoral establece como uno de sus objetivos «la protection des équilibres biologiques et écologiques, la lutte contre l'érosion, la préservation des sites et paysages et du patrimoine». La inclusión de este texto no es casual. La comunidad internacional trabajaba ya desde hacía tiempo en los trabajos previos que desembocarían en la Cumbre de la Tierra de Río de Janeiro (1992), y en la que se formularon las bases teóricas del desarrollo sostenible. La atención a la degradación de los ecosistemas, entre los cuales el litoral es uno de los más frágiles, alcanzará su punto más alto cuando, en 1987, se haga público el informe de la Comisión Mundial de Medio Ambiente y Desarrollo de las Naciones Unidas, Our Common Future ${ }^{4}$.

Es en ese momento de toma de conciencia global en el que debemos contextualizar la aprobación de la ley de costas española, en la cual la propiedad privada ocupaba enclaves de extraordinario valor ambiental, y donde la legislación anterior había amparado una elevada densidad urbana de la costa. No obstante, no puede ignorarse la existencia de factores internos que explican que sea en ese momento en el que una nueva ley de costas, inspirada por estos principios, pueda ver la luz.

El 22 de junio de 1986 se celebraron elecciones generales en España, en las que el Partido Socialista revalidó su mayoría absoluta. Sin embargo, dicho éxito electoral quedaba empañado por la pérdida de 18 escaños con respecto a los comicios anteriores. El principal partido de la oposición (Coalición Popular, más tarde Partido Popular) estaba liderado por Manuel Fraga, que fue ministro de Información y Turismo en el régimen franquista, entre julio de 1962 y octubre de 1969, y, por tanto, principal artífice de la primera ley de costas, aprobada en abril de ese último año. La aprobación de un nuevo texto, que estuviera inspirado por los principios de conservación de los ecosistemas y por la recuperación de espacios privatizados para el uso público, requería de un consenso extraordinario en el Parlamento -lo que no era posible ${ }^{5}$ o bien de una mayoría absoluta. El resultado

4 Popularmente conocido como Informe Brundtland en honor a su redactora principal, la doctora finlandesa Gro Harlem Brundtland, futura directora general de la OMS.

5 Tras las elecciones de 1986, el Parlamento ofrece una extraordinaria fragmentación: de doce formaciones políticas representadas, ocho tienen carácter regionalista (Partido Aragonés Regionalista, Unión Valenciana, Agrupación Independientes de Canaria), nacionalista (Coalición Galega, Convergència i Unió, Partido Nacionalista Vasco, Euskadiko Eskerra) o incluso independentista (Herri Batasuna). Todas ellas sumaban exactamente el $10 \%$ de la Cámara (35 escaños sobre 350). 
de las elecciones de junio de 1986 permite este nuevo escenario, de manera que el partido socialista, que había aplazado esta reforma legal durante su primera legislatura (1982-1986), puede iniciar así los trámites para la redacción del nuevo texto sobre costas, sabedor de que el descenso del respaldo electoral le obligaba a actuar con rapidez y a culminar esta tarea dentro del plazo de la legislatura, para no depender de un futuro cambio de gobierno, una moción de censura o estar condicionado por reivindicaciones de los partidos regionalistas o nacionalistas.

\section{UNA APARENTE REVOLUCIÓN: LA LEY 22/1988, DE COSTAS}

\subsection{Las reacciones previas al nuevo texto legal}

Pero esos trámites -a pesar de su relativa agilidad, si los comparamos con la tramitación del texto anterior- iban a convulsionar el panorama municipal español entre 1986 y 1988. Con el lema Recuperemos la costa, el Ministerio de Obras Públicas iniciaba una campaña en la que se daban a conocer las líneas básicas de la nueva ley que se estaba tramitando en el Parlamento. De entre las nuevas disposiciones destacaba, con mucho, la aparición de una servidumbre de protección de cien metros, frente a los veinte que hasta entonces aseguraba la servidumbre de vigilancia de la ley de 1969. En esa franja, cinco veces mayor, no estarían permitidos los usos residenciales ni hoteleros. Al mismo tiempo, se iban a incorporar al dominio público otros bienes hasta entonces excluidos, como dunas, acantilados y los espacios ganados al mar como consecuencia directa o indirecta de obras, que, como hemos visto, con el texto anterior habían pasado a ser de propiedad privada.

Pero si estas modificaciones tienen una enorme trascendencia y repercusión social, destaca -incluso por encima de ellas- el hecho de que la nueva ley de costas excluye expresamente la posibilidad de que haya propiedad privada en el dominio público (Disposición Transitoria $1^{a}$ ), incluso aunque ésta se encuentre inscrita en el registro de la propiedad y sus propietarios hayan satisfecho puntualmente el pago de las tasas municipales, cuenten con escritura legal y hubieran adquirido su vivienda conforme a derecho. La nueva ley convierte así a los propietarios a los que un nuevo deslinde haya situado dentro del dominio público, en titulares de un derecho de ocupación del dominio público, en régimen de concesión administrativa sobre el demanio, durante treinta años prorrogables por otros treinta. Los cambios propuestos, por tanto, eran de tal magnitud que provocaron reacciones inmediatas en los medios de comunicación, que hablaron del peligro que el nuevo texto representaba para la propiedad de numerosos edificios ${ }^{6}$.

6 Diario Información, 12 de agosto de 1988 (ver en TORRES, 2009). 
Pero, aunque esta reacción pueda ser comprensible, las mayores repercusiones vinieron de la actitud de los ayuntamientos costeros, especialmente en la fachada mediterránea, que, alertados por las noticias que llegaban de la tramitación de la ley, y sus ambiciosos planteamientos, resolvieron reelaborar precipitadamente sus documentos de ordenación urbana (Planes Generales de Ordenación, en la mayor parte de los casos), entre los años 1985 y 1987, reclasificando suelo de forma vertiginosa con el fin de transformar el suelo no urbanizable en urbanizable, con planeamiento parcial aprobado, cuando no directamente en suelo urbano. De este modo el alcance de la servidumbre de protección quedaba limitado a los 20 metros originales, y, conforme a lo establecido en la Disposición Transitoria $3^{a}$ de la Ley (y $9^{a}$ de su Reglamento), se respetarían los usos y construcciones existentes ${ }^{7}$.

Con este dato es posible comprender la información que se expresa en la tabla 1. En ella se expresa el porcentaje de la longitud de la costa de cada provincia (o isla, en el caso de los archipiélagos) que está afectado por una servidumbre de protección de $20 \mathrm{~m}$ o de $100 \mathrm{~m}$. Bajo el primero de los casos se encuentran los terrenos clasificados -a la entrada en vigor de la ley- como suelo urbano o urbanizable con programa de urbanización. Es decir, suelo consolidado bajo la edificación en la mayor parte de los casos. La columna de $100 \mathrm{~m}$ acoge los suelos que, en el momento de la aprobación de la Ley, estaban clasificados como no urbanizables o bien urbanizables sin programa de ejecución (suelo urbanizable no programado, según la terminología del momento, hoy derogada).

A la vista de la tabla, se advierte que la situación, en el momento de la entrada en vigor de la Ley, distaba mucho de la deseable. Cinco provincias (de norte a sur: Girona, Barcelona, Valencia, Alicante y Málaga) contaban con más del $60 \%$ de su costa clasificada como urbana o similar en el momento en el que la ley entra en vigor. A ellas deberemos añadir tres más (en el mismo orden, Tarragona, Castellón y Granada), en las que el porcentaje oscilaba entre el 40 \% y el 60\%. Y, con la única excepción de Almería, toda la costa mediterránea española (más las mayores islas de los dos archipiélagos) se encontraba plenamente urbanizada por encima del $30 \%$. Todos esos espacios consolidados quedarían al margen de las determinaciones más ambiciosas de la ley: la servidumbre de protección afectaría sólo a los 20 primeros metros, y se respetarían usos y construcciones existentes, salvo nuevo deslinde que determinara la situación en el dominio público.

7 Para el caso de la provincia de Alicante, por ejemplo, en 1985 aprueban la reforma de su documento de ordenación municipal Elche, Santa Pola y Guardamar del Segura. En 1986 lo harán Teulada, Poble Nou de Benitatxell y Torrevieja. En 1987: Denia, L'Alfaç del Pi y Alicante. Nueve municipios de un total de diecinueve costeros. 
Tabla 1. Porcentaje de costa en los que se aplicaba una servidumbre de proteccion de 20 y de 100 mts en julio de 1988

\begin{tabular}{|c|c|c|}
\hline $\begin{array}{l}\text { PROVINCIA } \\
\text { (O ISLA) }\end{array}$ & $20 \mathrm{~m}$ & $100 \mathrm{~m}$ \\
\hline Alicante & 64.00 & 36.00 \\
\hline Almería & 18.00 & 82.00 \\
\hline Asturias & 6.30 & 93.70 \\
\hline Barcelona & 79.00 & 21.00 \\
\hline Cádiz & 33.00 & 67.00 \\
\hline Cantabria & 12.50 & 87.50 \\
\hline Castellón & 44.70 & 55.30 \\
\hline Coruña, La & 15.00 & 85.00 \\
\hline Formentera & 3.38 & 96.62 \\
\hline Fuerteventura & 3.80 & 96.20 \\
\hline Girona & 80.00 & 20.00 \\
\hline Gomera, La & 15.00 & 85.00 \\
\hline Gran Canaria & 43.50 & 56.50 \\
\hline Granada & 42.77 & 57.23 \\
\hline Guipúzcoa & 13.60 & 86.40 \\
\hline Hierro, El & 5.00 & 95.00 \\
\hline
\end{tabular}

\begin{tabular}{|c|c|c|}
\hline $\begin{array}{l}\text { PROVINCIA } \\
\text { (O ISLA) }\end{array}$ & $20 \mathrm{~m}$ & $100 \mathrm{~m}$ \\
\hline Huelva & 9.00 & 91.00 \\
\hline Ibiza & 11.53 & 88.47 \\
\hline Islotes Baleares * & 0.00 & 100.00 \\
\hline Lanzarote & 28.30 & 71.70 \\
\hline Lugo & 12.00 & 88.00 \\
\hline Málaga & 66.00 & 34.00 \\
\hline Mallorca & 33.64 & 66.36 \\
\hline Menorca & 15.69 & 84.31 \\
\hline Murcia & 34.86 & 65.14 \\
\hline Palma, La & 25.00 & 75.00 \\
\hline Pontevedra & 20.00 & 80.00 \\
\hline Sevilla & 1.20 & 98.80 \\
\hline Tarragona & 40.00 & 60.00 \\
\hline Tenerife & 35.00 & 65.00 \\
\hline Valencia & 63.60 & 36.40 \\
\hline Vizcaya & 35.52 & 64.48 \\
\hline
\end{tabular}

*: Islotes Baleares: Dragonera y Cabrera

Fuente: Torres (1997). Elaboración propia

Sólo Vizcaya aparece altamente urbanizada en la fachada cantábrica, aunque por motivos diferentes, ligados al desarrollo urbano e industrial de la ría de Nervión (área metropolitana del Gran Bilbao), y no a fenómenos relacionados con la urbanización de uso turístico. 


\subsection{Principales novedades de la ley $22 / 1988$}

Desde sus inicios, el nuevo texto representa una ruptura con el ordenamiento anterior. Su planteamiento inicial no puede ser más contrario a la política anterior: «la presente ley establece la prevalencia de la publicidad de este dominio natural y posibilita además su inscripción registral [a favor de la Administración] (...) de este modo se excluye la posibilidad de consolidar la apropiación por particulares de terrenos de dominio público» ${ }^{8}$. Se habla repetidas veces de conservación de los espacios, de la necesidad de recuperar para el uso público los terrenos ocupados, y, en fin, se ofrece una perspectiva radicalmente contraria a la existente hasta la fecha. Las principales aportaciones -o novedades- que incorpora el nuevo ordenamiento son las siguientes:

- Se amplía notablemente la lista de bienes pertenecientes al dominio público. No sólo se trata de la inclusión de espacios hasta entonces no considerados, como las dunas, los acantilados o los terrenos ganados al mar, sino que incluso aquellos bienes que ya existían (playas, zona marítimo terrestre) reciben una nueva definición, más amplia y acorde con la realidad ecológica litoral. Así, las playas -que siguen siendo zonas de depósito de materiales sueltos- ya no dependerán, sin embargo, de la ausencia de vegetación o de que ésta sea escasa y característica, como se exigía en el art. 1.1. de la ley de costas de 1969. La zona marítimo-terrestre, por su parte, ya no tendrá como límite interior el espacio alcanzado por las mayores olas en los temporales ordinarios, sino las olas en los mayores temporales conocidos?.

- Se incluye un nuevo bien de dominio público, fruto de la suma de otros cuatro, y que servirá de referencia espacial para las mediciones de las servidumbres. Se trata de la ribera del mar, nuevo término (aunque de origen medieval) que engloba la zona marítimo-terrestre -ya definida-, los espacios húmedos con relación superficial o subterránea con el mar (albuferas, marjales, marismas), la playa y las dunas. El límite interior de la ribera del mar, es decir, la parte posterior del último de los cuatro elementos citados que exista, será el que marque la línea de deslinde, lugar desde el cual se computarán los metros que definan las servidumbres ${ }^{10}$.

8 Ley 22/1988, de Costas. Exposición de Motivos, apartado IV.

9 Artículo 1.2 de la ley de costas de 1969, y artículo 3.1.a de la ley de costas de 1988, respectivamente.

${ }^{10}$ La nueva ley homogeneita, por tanto, el lugar desde el que se establecen las mediciones. Con el texto anterior, los veinte metros de la servidumbre de salvamento se contaban desde el límite interior de la zona marítimo-terrestre, mientras que la servidumbre de vigilancia litoral dejaba libres seis metros, pero contados desde la línea de mayor pleamar, y, por tanto, desde un lugar que no tenía por qué ser coincidente con el anterior (artículos 4.2 y 4.6 de la ley de costas de 1969). 
- Las servidumbres siguen siendo tres, pero cambian sus nombres y, sobre todo, sus dimensiones y los objetivos de su clasificación, así como los usos permitidos en ellas. Dos de ellas, contadas desde el límite interior de la ribera del mar, son paralelas a la costa; mientras que la tercera será perpendicular: - La servidumbre de protección, que ocupará 20 o 100 metros, dependiendo del tipo de suelo sobre el que se asiente: 20 metros en suelos urbanos y urbanizables con planeamiento parcial aprobado, y 100 metros en suelos no urbanizables o bien urbanizables pero sin dicho planeamiento parcial. Sustituye a la anterior servidumbre de salvamento. En esta servidumbre están prohibidos los usos residenciales y hoteleros, aunque no la propiedad privada. La competencia en este espacio para el otorgamiento de licencias y permisos de ocupación corresponde a las comunidades autónomas y a los ayuntamientos.

- La servidumbre de tránsito, especialmente concebida para el trazado de paseos marítimos (artículos 27 y 44.5 de la ley), y cuya anchura será de 6 metros, aunque podrán llegar a veinte en los lugares de tránsito difícil o peligroso (por ejemplo, para dar acceso a calas en la base de un acantilado). Sustituye a la anterior servidumbre de vigilancia litoral. La medición de los seis metros se produce desde el mismo punto, por lo que no son acumulables (es decir, serían 100 metros, de los cuales los 6 primeros son tránsito y los demás protección). Están prohibidos los usos permanentes y la propiedad privada. Sólo se podrán asentar usos en régimen de concesión (por ejemplo, restaurantes en el paseo marítimo) siempre que no exista ubicación alternativa. La administración competente en este espacio es la central, a través de la Dirección General de Costas (o Dirección General de Sostenibilidad de la Costa y del Mar, según la denominación de 2009).

- Servidumbre de acceso al mar, que sustituye a la anterior servidumbre de paso, y para la cual, en esta ocasión, sí se especifican dimensiones y usos: en los lugares urbanizados se garantizará un acceso libre, público y gratuito a las costas cada 200 metros para uso peatonal, y cada 500 metros para uso rodado (se entiende que para vehículos de limpieza, vigilancia o salvamento, no para acceso rodado de vehículos particulares). Al tratarse de pasos expeditos, no puede haber ningún uso en ellos, ni temporal ni permanente. Su titularidad es estatal ${ }^{11}$.

${ }^{11}$ No obstante, conviene precisar que, según diversas sentencias del Tribunal Constitucional, «la titularidad del dominio público no es, en sí misma, criterio de delimitación competencial». Sentencias del TC 77/84, 227/1988 y 103/1989. 
- Los titulares de propiedades adquiridas con anterioridad a la entrada en vigor de la ley, y que, tras practicarse el oportuno deslinde, hubieran quedado dentro del dominio público, pasarán a ser titulares de un derecho de ocupación temporal del mismo, perdiendo su propiedad y sin derecho a indemnización ${ }^{12}$. El legislador podía haber optado por una solución compensatoria de tipo económico, pero los precios de mercado en la primera línea del litoral mediterráneo son inalcanzables para la Administración, incluso haciendo valer los derechos de tanteo y de retracto. Se optó, pues, por una compensación en forma de concesión administrativa extensa de uso del dominio público (treinta años, prorrogables treinta más), trascurrida la cual, los inmuebles deberían ser derribados. Como es fácil imaginar, una medida de este tipo generó de inmediato una fuerte reacción por parte de los afectados, y -hay que decirlo- una pasividad general del resto de la ciudadanía, cuando no un sentimiento admirativo por el carácter expeditivo de la ley. Sin embargo, la aplicación de esta cláusula acabaría siendo tan compleja que, transcurridos veinte años de la puesta en marcha de la ley, la mayor parte de los expedientes está en manos de los tribunales de justicia y los derribos son excepcionales ${ }^{13}$.

- La pérdida de una propiedad adquirida legalmente antes de la entrada en vigor de la ley ha sido interpretada por algunos juristas como una aplicación retroactiva de la norma, lo que ha generado numerosos conflictos, como veremos. Pero, desde el punto de vista de los particulares, además de significar una desposesión, representa, además, un peligro físico por la amenaza que supone para la integridad de sus viviendas. En efecto, tal y como recoge el artículo 6 de la nueva ley:

1. «Los propietarios de los terrenos amenazados por la invasión del mar o de las arenas de las playas, por causas naturales o artificiales, podrán construir obras de defensa, previa autorización o concesión, siempre que no ocupen playa ni produzcan fenómenos perjudiciales en ésta o en la zona marítimo-terrestre, ni menoscaben las limitaciones y servidumbres legales correspondientes ${ }^{14}{ }$.

2. «En otro caso, los terrenos invadidos pasarán a formar parte del dominio público marítimo-terrestre, según resulte del correspondiente deslinde».

12 Disposición Transitoria $1^{\text {a }}$ de la ley de costas de 1988.

${ }^{13}$ Aunque, cuando se producen, van acompañados de un extraordinario despliegue mediático, que persigue trasladar a la opinión pública la impresión de que la ley es implacable con las ocupaciones del dominio público, aun cuando se trate de derribos infrecuentes.

${ }^{14}$ El subrayado es nuestro. 
Se produce así, no sólo una situación de desamparo por la pérdida de la propiedad, sino que se pone en grave riesgo a las estructuras y sus ocupantes, al impedirles realizar obras de mejora o refuerzo (incluso menores, como la sustitución de puertas y ventanas corroídas por la sal y la humedad) por encontrarse sobre dominio público. Parece haber un contrasentido entre el permiso que otorga la Administración para ocupar el lugar durante sesenta años y las dificultades impuestas a los ocupantes para ejercer ese derecho, incluso una vez desposeídos de la propiedad ${ }^{15}$. En estas condiciones, el transcurso del tiempo corre en contra de los concesionarios, que pueden ver incluso derribada su vivienda antes de que transcurra el periodo estipulado, si, por razones de seguridad, los técnicos municipales emiten una declaración de ruina tras un temporal marítimo.

Foto 1. Ocupaciones en régimen de concesión administrativa en primera línea de la playa de Islantilla, Huelva

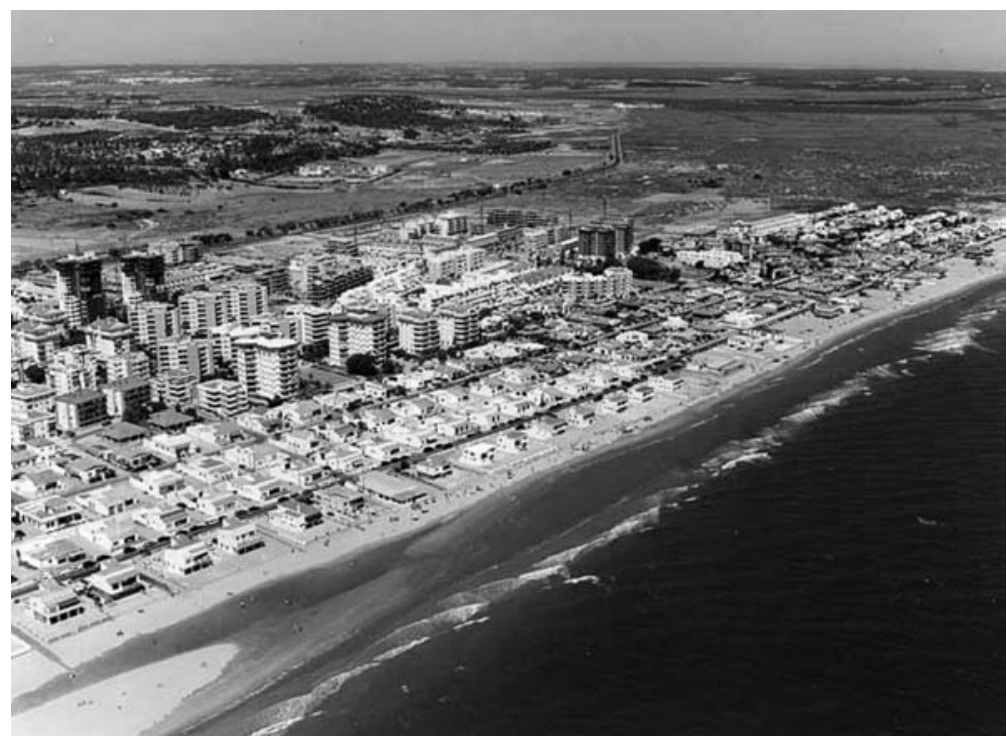

Foto: Guía de Playas del Ministerio de Medio Ambiente, y Medio Rural y Marino

${ }^{15}$ La pérdida de la propiedad implicaba, por supuesto, la incapacidad para venderla. Tan sólo en el caso de fallecimiento del titular, sus causahabientes podían subrogarse en los derechos de aquél, por el tiempo que restara de concesión y en las condiciones fijadas en su momento. Para reclamar esta subrogación se disponía de un año de plazo. Transcurrido este tiempo desde la muerte del titular, se entendía que renunciaban a la concesión (artículo 70.2). Como veremos, en 2009 se modifica este apartado. 
En casos como el de la imagen, no se trata de construcciones de uso turístico, sino asociadas al veraneo tradicional. Fueron edificadas en torno a los años cincuenta del pasado siglo, entre la playa y las dunas. Su ubicación interfiere en el intercambio de áridos, y, aunque legítima entonces, ha sido una de las causantes de la progresiva regresión de la playa.

\subsection{Análisis crítico de la ley de costas de 1988}

a) Una definición mejorable del objeto de análisis

En primer lugar, el texto de costas redactado en 1988 falla en lo más esencial, la relación entre el título y su contenido. La de España no es una ley de costas. No atiende a la interfase tierra-mar y, por sorprendente que parezca, ni siquiera define en todo su texto el concepto de costa. Tampoco podemos decir que se trate de una ley del litoral. El espacio marino del litoral no se desarrolla en la ley, sino que se regula subsidiariamente por los convenios internacionales (especialmente la III Convención de las Naciones Unidas sobre Derecho del Mar, firmada en 1982 pero en vigor desde 1994), y por la legislación nacional específica (leyes sobre el Mar Territorial, sobre la Zona Económica Exclusiva y sobre la Plataforma Continental). Y tampoco se da una regulación del espacio terrestre del litoral, más allá de algunas recomendaciones urbanísticas en la zona de influencia litoral ${ }^{16}$, que abarca los 500 metros contados a partir del límite interior de la ribera del mar, pero que, en cualquier caso, quedaban supeditadas a la legislación urbanística y a las competencias municipales establecidas en la Ley 7/1985, Reguladora de las Bases de Régimen Local. ¿Qué es, entonces? La ley 22 /1988, llamada de costas, es en realidad una ley de bienes de dominio público. Añade muchos bienes al demanio, los define con precisión -aunque, como veremos, hay excepciones-, repetidamente se alude a las limitaciones de usos y a los títulos de ocupación posibles en ellos, así como a las servidumbres que se establecen a partir del límite interior de la ribera del mar. Son, por tanto, disposiciones muy específicas, muy detalladas en sus pormenores y que afectan tan sólo a espacios muy concretos de la costa. Hay que añadir, además, que no toda la costa queda regulada por esta ley, ya que los puertos de interés general cuentan con dominio público portuario, que, aunque ocupa posición costera, dispone así de una regulación propia, dependiente del Ministerio de Fomento, a través de las respectivas Autoridades Portuarias, y ajena, por tanto, al texto 22/1988.

\footnotetext{
${ }^{16}$ Regulada por el artículo 30 de la Ley 22/1988, de costas.
} 
Y, aunque la Planificación y Gestión Integrada de Áreas Litorales sea un concepto posterior a la fecha de promulgación de la Ley (Barragán, 1994), el texto de 1988 podría haber dado cabida a la redacción de instrumentos de planificación, como directrices de ordenación del litoral, planes de actuación en el litoral o similares, que las distintas comunidades han venido desarrollando en estas últimas décadas, con objetivos -y logros- desiguales.

b) Una definición mejorable de algunos bienes de dominio público

Conviene, además, mencionar la deficiente definición geográfica que se hace de algunos bienes de dominio público. Pongamos algunos ejemplos:

- Las dunas se incorporan al dominio público en 1988, pero de manera estricta hasta su parte posterior, sin tener en cuenta que los sistemas dunares son móviles, y que, por tanto, precisan de una zona de amortiguación, de al menos una decena de metros tras ellos, que garantice su comportamiento seminatural.

- Tras la duna suele terminar la ribera del mar y, por tanto, el dominio público. Comienzan entonces a contarse las servidumbres, de las cuales la primera es la de tránsito. Es decir, inmediatamente tras la duna, sin necesidad legal de que exista un solo metro de separación, puede construirse un paseo marítimo. Y lo que resulta más llamativo, tras los seis metros de la servidumbre de tránsito comienzan los de la servidumbre de protección, que, en suelos no urbanizables, llegarían hasta los 100 metros, ampliables a 200. En esa extensa franja no se permite el uso residencial ni el hotelero, pero no existe limitación alguna a la propiedad privada. Es decir, tras la duna y el paseo marítimo es posible encontrar una valla o un muro que delimite una urbanización, siempre y cuando sus primeros metros estén destinados a usos no residenciales, como por ejemplo pistas de tenis, piscinas, locales comerciales o superficies deportivas en general. Es cierto que estos usos no generan un efecto pantalla ni sombras vespertinas en las playas expuestas a levante, pero resulta difícil entender que se conciban dentro de una servidumbre cuya filosofía es proteger el litoral (ver foto 2 ).

- También están mal definidos, desde un punto de vista geográfico, los acantilados. Se debe reconocer favorablemente su inclusión en el dominio público, pero ésta es limitada. Literalmente, el artículo 4.4 de la ley establece que forman parte del dominio público «los acantilados sensiblemente verticales, que estén en contacto con el mar o con espacios de dominio público marítimo-terrestre hasta su coronación». Por acantilados sensiblemente verticales debe entenderse aquellos que igualen 
o superen una pendiente de 60 grados sexagesimales con la horizontal ${ }^{17}$. Se protege, por tanto, tan sólo la pendiente del acantilado (hasta su coronación, tras la cual contarían las servidumbres) e indistintamente de los materiales que lo formen. Sin embargo, no tiene la misma evolución un acantilado de margas que uno de granito o de pizarra, y la ley debería haber previsto la extraordinaria influencia de la litología en la formación y evolución (por tanto, en la cambiante pendiente) de los acantilados.

Foto 2. Playa de Islantilla (Huelva, Andalucía)

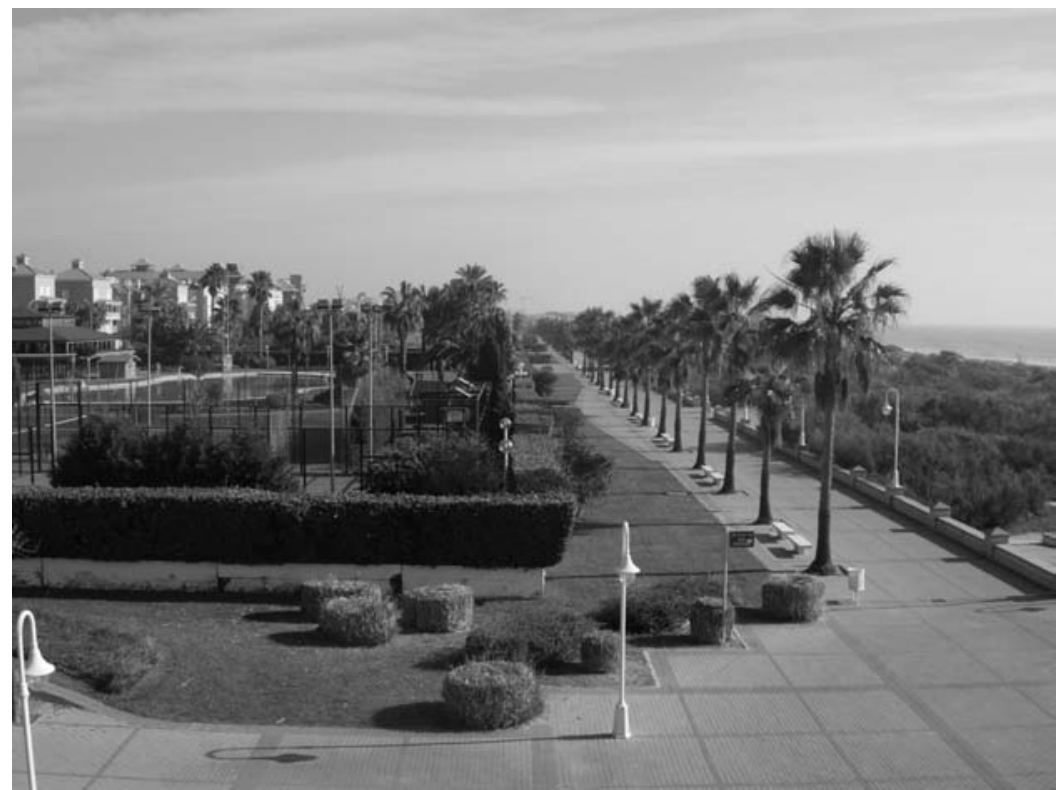

La urbanización, desarrollada conforme a la Ley de Costas de 1988, debe respetar las servidumbres de tránsito ( $6 \mathrm{~m}$, ocupada por el paseo marítimo) y de protección ( 94 metros restantes) tras el límite interior de la ribera del mar. Como se puede apreciar, los usos emplazados en este lugar no son residenciales, pero no contribuyen a proteger los bienes de dominio público. Foto del autor

c) Una norma tardía... y temerosa

En la tabla 1 ya se ofrecían los datos que mostraban que la ley llegaba tarde para frenar el proceso de urbanización del litoral español, particularmente de la fachada mediterránea. La reacción de muchos municipios, clasificando suelo y

${ }^{17}$ Art. 6.3 del Reglamento de la Ley de Costas, aprobado por Real Decreto 1471/1989, de 1 de diciembre. 
acelerando la aprobación de sus documentos de planeamiento, limitó en buena medida las posibilidades de aplicación máxima de las determinaciones legales de costas. La propia norma es consciente de esto, y establece, en su disposición transitoria tercera, la obligación de revisar los planes parciales aprobados con posterioridad al 1 de enero de 1988. Teniendo en cuenta que la norma se aprueba en julio ${ }^{18}$, el legislador tan sólo revisará el planeamiento aprobado en los siete meses anteriores, incluso a sabiendas de la extraordinaria celeridad con la que se habían aprobado planes generales y parciales de ordenación municipal en los años previos.

Sin duda, la revisión de los planes aprobados en 1986 y 1987 -periodo de tramitación de la ley de Costas en el Parlamento y en el Senado- habría ocasionado numerosos contenciosos administrativos con los ayuntamientos, y habría obligado a suspender cautelarmente la aplicación de los Planes de Ordenación Urbana sometidos a examen. Pero la Administración Central no quiso abordar este problema, y se prefirió optar por una actitud timorata, ignorando lo sucedido en los años previos y sin exigir responsabilidad alguna a los municipios, una actitud que contrasta, de nuevo, con la firmeza mostrada con los particulares.

Otro aspecto en el que el legislador de 1988 se muestra temeroso es a la hora de encarar una tarea de gran complejidad, pero imprescindible para la correcta aplicación de la ley de costas: el deslinde. La ley de 1969, a pesar de sus disposiciones favorables a la privatización del litoral, establecía un plazo de cinco años para que la Administración central tuviera terminado el deslinde del dominio público marítimo-terrestre (DPMT). Pero no sólo no estuvo hecho, sino que, cuando se aprueba la ley de costas de 1988, éste está, en su mayor parte, pendiente.

La norma de 1988 no aborda el problema de los plazos, tan sólo establece que, "para la determinación del dominio público marítimo-terrestre se practicarán por la Administración del Estado los oportunos deslindes» ${ }^{19}$. El hecho de no establecer plazo alguno indica, implícitamente, el reconocimiento de la complejidad de la tarea, y evidencia una clara ausencia de voluntad política.

La situación del deslinde, según los últimos datos oficiales facilitados por el Ministerio de Medio Ambiente y Medio Rural y Marino, y que corresponden al 30 de junio de 2009, es la siguiente:

${ }^{18}$ La ley aparece publicada en el Boletín Oficial del Estado no 181, de 29 de julio de 1988.

${ }^{19}$ Artículo 11 de la ley 22 /1988, de costas. 
Figura 2. Porcentaje de longitud de costa de cada provincia en el que ya se ha realizado el deslinde del dominio público marítimo-terrestre

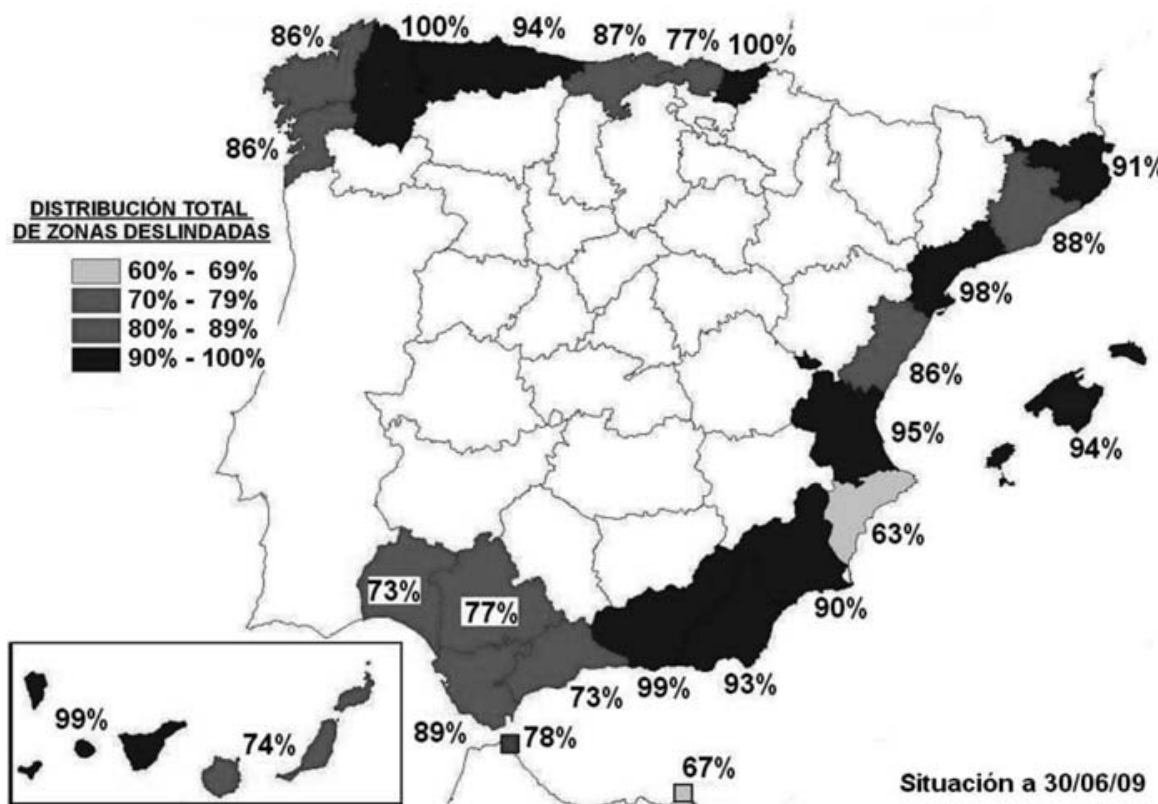

Fuente: Dirección General de Sostenibilidad de la Costa y del Mar, Ministerio de Medio Ambiente y Medio Rural y Marino. http://www.mma.es/portal/secciones/aguas_marinas_litoral/gdpmt/deslinde.htm [consulta: 10 diciembre 2009]

Los datos facilitados por la Administración evidencian una notable mejora con respecto a años anteriores. Por ejemplo, se ha pasado de un 70 $\%$ de la costa española deslindada el 30 de junio de 2005 (MMA, 2005) a un $87,19 \%$ cuatro años más tarde (MARM, 2009). El progreso se debe, sin duda, a la puesta en marcha del Plan Nacional de Deslindes (2004-2008), durante el que se realizó un incremento del esfuerzo presupuestario y técnico encaminado a culminar esta tarea. Así, mientras en 2003 se destinó a deslindar la costa 1,12 millones de euros, al año siguiente la cifra se incrementó casi un 48\%, alcanzando 1,65 M €, y los 3,33 M € en los primeros seis meses de 2005. El deslinde actual, próximo al 90\%, es casi total, y las longitudes deslindadas han experimentado un notable incremento desde el 15 de mayo de 2004, en que dio comienzo el mencionado plan, como se refleja en la tabla 2 .

Por provincias, el aumento de longitud deslindada entre 2005 y 2009 es notable en varios casos, como Murcia (que pasa de un $55 \%$ a un $90 \%$ de su longitud total) o el de las Islas Baleares (de 62 al 94\%). Cantabria, La Coruña y Almería también 
experimentan avances notables, en torno a un 25-27\% más de costa deslindada entre estos cuatro años. En otras provincias se ha avanzado menos, las hay incluso que se mantienen prácticamente igual (Sevilla, Alicante, Castellón y Girona, más las ciudades autónomas de Ceuta y Melilla), y se da el caso aparentemente extraño de Tarragona, que tiene menos longitud deslindada en 2009 que cuatro años antes.

Tabla 2. Longitud de costa deslindada anualmente en España (2004-2009)

\begin{tabular}{|c|c|}
\hline AÑO & $\begin{array}{c}\text { Deslindes realizados } \\
\text { ese año }(\mathbf{e n ~} \mathbf{~ k m})\end{array}$ \\
\hline 2004 & 361 \\
\hline 2005 & 483 \\
\hline 2006 & 543 \\
\hline 2007 & 604 \\
\hline 2008 & 590 \\
\hline 2009 & $450 *$ \\
\hline \multicolumn{2}{|c|}{$*$ Sólo hasta el 30 de junio de 2009} \\
\hline
\end{tabular}

Fuente: MARM, 2009. Elaboración propia

No obstante, si sometemos los datos a un análisis más detallado, se muestran algunas deficiencias, que no invitan al optimismo:

En primer lugar, que la costa española esté deslindada en un 87,19\% como media, por muy elevado que parezca el dato, debe ser entendido como un fracaso. Veinte años después de la aprobación del reglamento de la ley, y cuarenta años después de la primera ley de costas, España no ha terminado una tarea que es primordial para la ejecución de esta norma. Que aún esté por deslindar casi un $13 \%$ debe entenderse, pues, como un incumplimiento de la obligación legal de la Administración, con independencia del color político que haya estado en el gobierno.

Por otro lado, y aunque la cifra es mejor que la de años anteriores, esconde un matiz nunca difundido y frecuentemente ignorado: la fecha del deslinde. No todos los kilómetros de costa españoles deslindados lo están conforme a la ley de costas actual. Buena parte de ellos se deslindaron de acuerdo con la ley anterior y, por tanto, no incorporan ni las dunas, ni los acantilados, entre otras pertenencias al dominio público. Esto quiere decir que no sólo se trata de un deslinde sin completar, sino, además, pendiente de actualizar en muchos $\operatorname{casos}^{20}$. Como ejemplo de este hecho, baste decir que el municipio de Denia

${ }^{20}$ A este hecho se debe el dato aparentemente anómalo de Tarragona: se ha revisado el deslinde en algunos puntos de la provincia. 
Tabla 3. El estado del deslinde del dpmt en España. Comparación entre 2005 y 2009

\begin{tabular}{|c|c|c|c|c|}
\hline $\begin{array}{c}\text { Zona } \\
\text { costera }\end{array}$ & Provincia & $\begin{array}{c}\text { Porcentaje } \\
\text { deslindado } \\
(31.12 .2005)\end{array}$ & $\begin{array}{c}\text { Porcentaje } \\
\text { deslindado } \\
(30.06 .2009)\end{array}$ & $\Delta$ \\
\hline \multirow{7}{*}{$\begin{array}{l}\text { Cantábrico y } \\
\text { Galicia }\end{array}$} & Guipúzcoa & 99,89 & 100,00 & $+0,11 \%$ \\
\hline & Vizcaya & 70,19 & 77,00 & $+6,81 \%$ \\
\hline & Cantabria & 60,08 & 87,00 & $+26,92 \%$ \\
\hline & Asturias & 84,38 & 94,00 & $+9,62 \%$ \\
\hline & Lugo & 100,00 & 100,00 & 0 \\
\hline & La Coruña & 59,21 & 86,00 & $+26,79 \%$ \\
\hline & Pontevedra & 77,35 & 86,00 & $+8,65 \%$ \\
\hline \multirow{3}{*}{$\begin{array}{l}\text { Costa } \\
\text { atlántica } \\
\text { andaluza }\end{array}$} & Huelva & 63,51 & 73,00 & $+9,49 \%$ \\
\hline & Sevilla & 74,22 & 77,00 & $+2,78 \%$ \\
\hline & Cádiz & 81,55 & 89,00 & $+7,45 \%$ \\
\hline \multirow{11}{*}{$\begin{array}{l}\text { Costa } \\
\text { mediterránea }\end{array}$} & Málaga & 55,94 & 73,00 & $+17,06 \%$ \\
\hline & Granada & 93,64 & 99,00 & $+5,36 \%$ \\
\hline & Almería & 67,71 & 93,00 & $+25,29 \%$ \\
\hline & Murcia & 55,78 & 90,00 & $+34,22 \%$ \\
\hline & Alicante & 60,55 & 63,00 & $+2,45 \%$ \\
\hline & Valencia & 81,77 & 95,00 & $+13,23 \%$ \\
\hline & Castellón & 85,46 & 86,00 & $+0,54 \%$ \\
\hline & Islas Baleares & 62,41 & 94,00 & $+31,59 \%$ \\
\hline & Tarragona & 100,00 & 98,00 & $-2 \%$ \\
\hline & Barcelona & 75,97 & 88,00 & $+12,03 \%$ \\
\hline & Girona & 90,48 & 91,00 & $+0,52 \%$ \\
\hline \multirow{2}{*}{$\begin{array}{l}\text { Archipiélago } \\
\text { canario }\end{array}$} & Sta. Cruz Tenerife & 85,05 & 99,00 & $+13,95 \%$ \\
\hline & LP de Gran Canaria & 61,55 & 74,00 & $+12,45 \%$ \\
\hline \multirow{2}{*}{$\begin{array}{l}\text { Ciudades } \\
\text { autónomas }\end{array}$} & Ceuta & 77,79 & 78,00 & $+0,21 \%$ \\
\hline & Melilla & 67,02 & 67,00 & $-0,02 \%$ \\
\hline
\end{tabular}

Fuente: MMA (2005) y MARM (2009). Elaboración propia

(al norte de la provincia de Alicante), que tiene una longitud de costa de 20,3 $\mathrm{km}$, tenía deslindados, en junio de 2004, un total de 15,5 km (el 76,35 \%), pero de los cuales 14,6 lo estaban conforme a la ley de $1969^{21}$. No es un caso aislado; al contrario, la mayor parte de los deslindes en España deriva, aún

${ }^{21}$ Según datos obtenidos del Servicio de Gestión del Dominio Público Marítimo-Terrestre, del Ministerio de Medio Ambiente en esa fecha. 
hoy, de la aplicación de la ley anterior, ya derogada. Es cierto que, a veces, el cambio legal no obliga necesariamente a realizar un nuevo deslinde, por tratarse de zonas urbanas, o bien porque no existe en ese lugar ninguno de los bienes que se incorporan al dominio público en 1988. Pero la definición de zona marítimo-terrestre, como vimos, difiere sustancialmente entre los dos textos, así como la de la playa. Y si algo existe siempre en la costa, es zona marítimo-terrestre, entendida como el espacio afectado por las mareas o el oleaje en los temporales. Reconocerla y delimitarla es tarea indispensable para afrontar el deslinde.

En tercer lugar, la asignación presupuestaria destinada al litoral en España, aunque ha mejorado en los últimos diez años (ver figura 3), sigue siendo paupérrima. Casi 291 millones de euros se asignaron en 2009 a Actuaciones en la costa, nombre que recibe el programa 456D del Ministerio de Medio Ambiente y Medio Rural y Marino, destinado a la gestión del litoral y la costa, y que recoge las actuaciones de la Administración Central en este espacio.

Figura 3. Presupuesto asignado a la Dirección General de Costas (1996-2009)

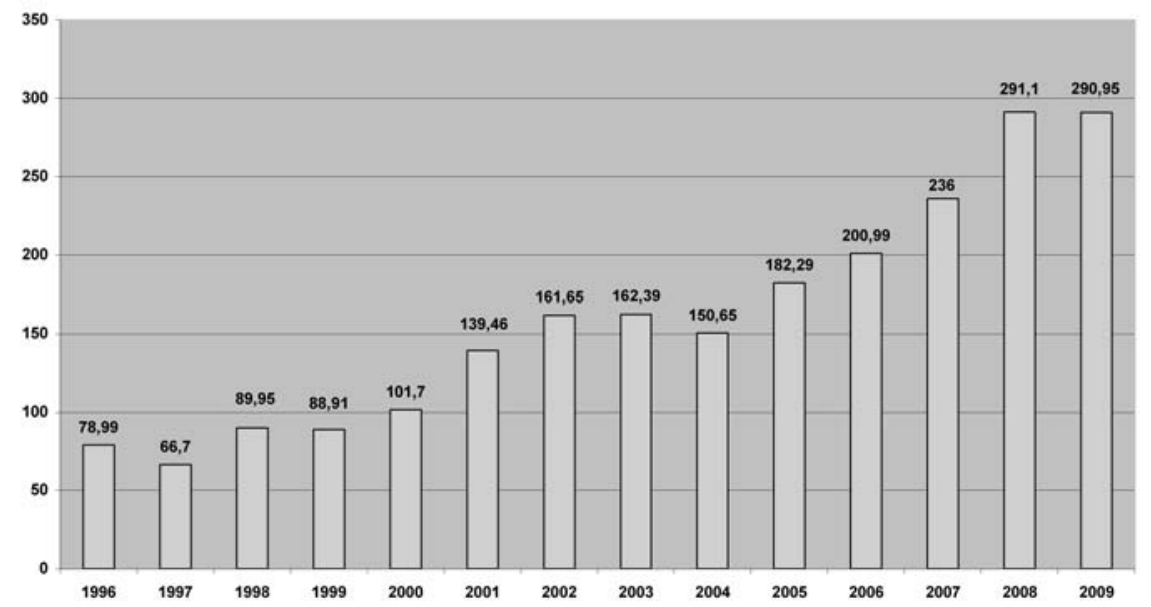

Fuente: Presupuestos Generales del Estado de los respectivos años. Elaboración propia

La cifra, aparentemente elevada, adquiere su verdadera dimensión si la comparamos, por ejemplo, con otras partidas del mismo ministerio: por ejemplo, la asignación del programa Desarrollo del medio rural fue, en 2009, de 1.381 millones de euros (casi cinco veces más), mientras que las destinadas al agua en general recibieron 1.919 (Gestión e infraestructuras del agua) y 619 (Calidad del 
agua) millones de euros, respectivamente ( $\mathrm{MEH}, 2009$ ). La partida destinada a costas, dentro del Ministerio de Medio Ambiente, es, como se ve, una de las que recibe menor atención. De hecho, a lo largo de los últimos años (2005-2008), las costas recibieron siempre menos del $10 \%$ de la asignación total del Ministerio de Medio Ambiente, conforme se explica en la tabla 4:

Tabla 4. Presupuesto destinado a la Dirección General de Costas (actualmente de Sostenibilidad de la Costa y del Mar) (2005-2009), para el programa Actuaciones en la Costa

\begin{tabular}{|c|c|c|}
\hline & $\begin{array}{c}\text { Presupuesto destinado al litoral } \\
\text { (programa Actuaciones en la costa del } \\
\text { Ministerio de Medio Ambiente) (en } € \text { ) }\end{array}$ & $\begin{array}{c}\text { Porcentaje de la inversión } \\
\text { en litoral sobre el total del } \\
\text { Ministerio de Medio Ambiente }\end{array}$ \\
\hline 2005 & 182.293 .360 & $8.78 \%$ \\
\hline 2006 & 200.989 .530 & $8.32 \%$ \\
\hline 2007 & 236.002 .860 & $9.98 \%$ \\
\hline 2008 & 291.095 .280 & $6.78 \%$ \\
\hline
\end{tabular}

Fuente: Ministerio de Medio Ambiente (llamado de Medio Ambiente y Medio Rural y Marino desde 2008). Elaboración propia

La merma en los dos últimos años se explica por el cambio de competencias del Ministerio del que depende el litoral. En España, las competencias estatales en materia de litoral se ejercían a través del Ministerio de Medio Ambiente desde 1996, y hasta abril de 2008. El 12 de abril de 2008 se aprueba el Real Decreto 432/2008, por el que se configura el Ministerio de Medio Ambiente y Medio Rural y Marino (MARM), de nueva creación, que asume las competencias hasta entonces atribuidas a los suprimidos Ministerios de Agricultura, Pesca y Alimentación - por un lado- y de Medio Ambiente, por otro, además de la competencia en materia de protección del mar, para la cual se prevé una necesaria colaboración con el Ministerio de Fomento, del que dependen los puertos de interés general ${ }^{22}$. La creación del nuevo macro-ministerio, cuyo pre-

22 Son Puertos de Interés General aquellos en los que se cumple alguna de estas circunstancias: efectúan actividades comerciales internacionales, su zona de influencia afecta de forma relevante a más de una comunidad autónoma o sirven a industrias estratégicas para el Estado y su economía, entre otras (artículo 5 de la ley 27/1992, de puertos del Estado y de la marina mercante). 
supuesto global es ahora el doble que el del anterior de Medio Ambiente (sobre todo debido a la asunción de Agricultura), conlleva que la partida destinada a litoral, aun siendo similar (ligeramente superior a 290 millones de euros), represente sólo el 2,20 \% del total ministerial en $2009^{23}$ en vez del casi $10 \%$ de los años anteriores.

Si la comparación se establece con otros ministerios, entonces advertimos la verdadera dimensión del gasto destinado al litoral en España. Por ejemplo, el programa Subvenciones y apoyo al transporte terrestre, del Ministerio de Fomento, recibió en 2009 737,7 millones de euros (MEH, 2009), 2'5 veces el presupuesto para gestionar y ordenar todo el litoral. Mención aparte merecen los grandes capítulos presupuestarios de este ministerio, como Creación de infraestructuras de carreteras $(2.918,51 \mathrm{M} €)$ o Infraestructura del transporte ferroviario $(2.092,66 \mathrm{M}$ $€)$, grandes consumidores de los recursos económicos de la nación. No se trata de cuestionar el gasto de estos capítulos, sin duda imprescindibles para dotar a España de unas infraestructuras competitivas y modernas, pero los datos dejan en evidencia que la prioridad inversora del Estado no es -no lo ha sido nuncaculminar la ordenación del litoral ${ }^{24}$.

Pues bien, dentro de esta exigua cantidad económica, la partida asignada a los deslindes nunca ha superado el 5\% del total en los últimos años, con mínimos ridículos del 0'55 \% en 2003, frente al 60\% destinado a regeneraciones de playas con aportes artificiales de arenas. En estas condiciones, se comprende sin dificultad que, más de veinte años después de la aprobación de la ley de costas, el estado español aún no haya culminado la tarea -obligatoria- de delimitar en su totalidad el dominio público marítimo-terrestre.

A estas tres cuestiones mencionadas, con las que se justifica el calificativo de temerosa de la ley, hay que añadir una cuarta, relacionada con la anterior. ¿Por qué la Administración Central no acomete esta tarea de una vez por todas, dedicando definitivamente los recursos económicos, técnicos y humanos necesarios? Bajo nuestro punto de vista, la principal razón se deriva precisamente de las anteriores: la aprobación tan tardía de la ley ha generado, a su vez, una situación

${ }^{23}$ Con el nuevo ministerio cambia también la denominación del órgano competente en el litoral: la histórica Dirección General de Costas recibe, desde abril de 2008, el nombre de Dirección General de Sostenibilidad de la Costa y del Mar.

24 Las comparaciones pueden alcanzar el esperpento si atendemos al presupuesto de, por ejemplo, una universidad medio-grande como la de Valencia, cuyo gasto aprobado para 2009 fue 381,75 M €, 90 millones de euros más que la dotación asignada para todas las actuaciones a realizar por el Estado en el litoral español ese año. La mayor universidad de España, la Complutense de Madrid, tuvo un presupuesto en 2008 de 607,2 millones de euros, más del doble de la cantidad asignada a la Dirección General de Costas para ese año, que fue de 291 millones de $€$. 
de ocupación tal que cualquier medida que se tome -y más una tan contundente como la retirada de la propiedad privada- acaba irremisiblemente en manos de la justicia administrativa, demostrando que la complejidad del problema es muy superior a la que aparentemente el legislador que elaboró la ley de costas parecía presuponer.

d) Una norma de aplicación muy polémica incluso hoy día. El informe Auken

En efecto, la aplicación rigurosa de la ley, especialmente en lo que corresponde a la transformación de propietarios en concesionarios, y las demoliciones de concesiones extinguidas sin derecho a indemnización, plantean un problema legal de primer orden, para el que no se ha dotado de especiales instrumentos -ni medios- a la justicia ordinaria. En la mayor parte de las ocasiones, las actuaciones de costas acaban resolviéndose en los tribunales, en dilatados procesos que las partes (particulares y las distintas administraciones implicadas) agotan hasta llegar a instancias como el Tribunal Supremo y, excepcionalmente, a la Audiencia Nacional. Estos complejos procesos judiciales demoran en ocasiones la veintena de años, y a veces más. Por citar un ejemplo, en el momento de redactar estas líneas, aún está pendiente de resolver por el Tribunal Supremo la situación de dos edificios en La Albufereta (Alicante) construidos a principios de los años sesenta y dentro del dominio público según un deslinde de 1974 (TORRES, 2009).

Por último, para terminar este análisis crítico de las repercusiones de la ley de costas, hay que mencionar, como ya se adelantaba, la enorme tensión social generada por su aplicación, así como los agravios comparativos entre propietarios, ya que, como se ha explicado, según las disposiciones de la ley, la clasificación del suelo es trascendente a la hora de definir la situación legal de los edificios situados en él. Sin embargo, la población en general suele asimilar que el criterio diferenciador es -o debería ser- la distancia a la línea de costa. Se dan así situaciones insólitas por las cuales es factible el derribo de unas viviendas situadas a más distancia del agua que otras, inmediatas al mar, que son respetadas por estar establecidas en suelo clasificado como urbano. De entre los recientes, el caso que más repercusión tuvo en los medios de comunicación fue la demolición de 23 viviendas en Cho Vito (municipio de Candelaria, isla de Tenerife), en octubre de $2008^{25}$. Hasta abril de 2009, la administración central había ordenado la demolición de 1.246 viviendas en primera línea de costa, la mayor parte de

${ }^{25}$ La noticia del desalojo de los 60 inquilinos fue recogida en todos los medios de comunicación nacionales, tanto de prensa escrita como audiovisuales (TORRES, 2009). 
ellas ilegales, es decir, sin título de ocupación del DPMT ${ }^{26}$, y, sólo en determinados casos, por extinción de la concesión.

Como consecuencia directa de estas actuaciones, se constituyó, en enero de 2008, la Plataforma Nacional de Afectados por la Ley de Costas, que agrupa a particulares -unos 20.000, según sus propias cifras- cuyas viviendas se encuentran amenazadas por órdenes de derribo por invadir el DPMT, según el deslinde practicado. No es la primera de las asociaciones constituidas para dar asistencia letrada a los propietarios convertidos en concesionarios, pero sí es la que ha logrado concitar mayor respaldo ciudadano y una mayor repercusión en los medios de comunicación y en los tribunales, hasta el punto de presentar, en febrero de 2008, una queja ante el Parlamento Europeo por «defectos técnicos de la ley», que desembocaban, a su juicio, en una aplicación retroactiva y abusiva de la ley de costas. La Comisión de Peticiones del Parlamento Europeo (competente en la tramitación de denuncias sobre la vulneración de la legislación europea en materia de medio ambiente, protección de los consumidores, empleo y política social) decidió admitir la queja el 16 de julio de ese mismo año ${ }^{27}$, y los estudios elaborados a raíz de ella culminaron en la presentación del llamado informe Auken ${ }^{28}$, para el que se tuvo en cuenta -entre otros documentos- esta queja de la Plataforma de Afectados.

El informe Auken del Parlamento Europeo se hizo público el 26 de marzo de 2009, con el título Impacto de la urbanización extensiva en España en los derechos individuales de los ciudadanos europeos, el medio ambiente y la aplicación del derecho comunitario. Su contenido es extraordinariamente crítico con la aplicación de la ley de costas en España, al considerar «que la mencionada Ley de Costas afecta de manera desproporcionada a los propietarios particulares de bienes, cuyos derechos deberían verse plenamente respetados, y, al mismo tiempo, no tiene un impacto suficiente en los auténticos autores de la destrucción costera, responsables en muchos casos de unos desarrollos urbanísticos excesivos en las costas, incluidos complejos vacacionales, y que estaban mejor situados para saber que

${ }^{26}$ Los títulos de ocupación temporal posibles del DPMT en España son cuatro: concesiones, autorizaciones, reservas de suelo y adscripciones. Los dos primeros se pueden otorgar a particulares (por ejemplo, para instalar servicios de temporada en las playas, como el alquiler de tumbonas y sombrillas). Los dos últimos son títulos de ocupación para la Administración central (reservas) o autonómica (adscripciones), para instalaciones militares, portuarias o de infraestructuras.

${ }^{27}$ El País, 7 de septiembre de 2008.

${ }^{28}$ El informe Auken o de Auken se conoce por el apellido de su redactora, Margrete Auken, diputada danesa del Grupo Los Verdes/Alianza Libre Europea. La versión en español del texto completo del informe se puede consultar en el siguiente enlace abreviado: http://tinyurl. com/ycn2pns. 
su actuación era sin duda contraria a las disposiciones de la ley en cuestión ${ }^{29}$. El informe acusa directamente a todas las administraciones -central, autonómicas y locales- como «responsables de haber puesto en marcha un modelo de desarrollo insostenible, que ha tenido gravísimas consecuencias, por supuesto medioambientales y, además, sociales y económicas» ${ }^{30}$.

Redactado, como se ve, en términos de gran dureza, el informe esgrime 39 considerandos críticos con la aplicación arbitraria de la ley, la impunidad de las actuaciones de la administración española y la ausencia de respeto a los derechos de los propietarios, especialmente en lo que respecta a la falta de una legítima indemnización económica por la pérdida de su propiedad. Tras su exposición, plantea 36 peticiones y/o exigencias a la administración española, entre las que aquí interesa destacar la que «pide a las autoridades españolas que velen por que ningún acto administrativo que obligue a un ciudadano a ceder su propiedad privada adquirida legítimamente, encuentre su fundamento jurídico en una ley adoptada después de la fecha de construcción de la citada propiedad ${ }^{31}$, por entender que sería contrario al principio de irretroactividad de los actos administrativos, que es un principio general del Derecho comunitario. Opina, igualmente, «que las personas que hayan adquirido de buena fe una propiedad en España y se hayan encontrado con que ha sido declarada ilegal deben tener derecho a obtener una indemnización adecuada a través de los órganos jurisdiccionales españoles» ${ }^{32}$, y, en suma, anima directamente a una modificación de la ley de costas, al instar a las autoridades españolas «a que revisen urgentemente y, en su caso, modifiquen la Ley de Costas a fin de proteger los derechos de los legítimos propietarios de viviendas y de aquellos que poseen pequeñas parcelas en zonas de la costa que no tienen un impacto negativo sobre el medio ambiente costero», haciendo hincapié «en que dicha protección no debe concederse a proyectos de desarrollo especulativos que no respetan las directivas de la UE en materia de medio ambiente» ${ }^{33}$.

La repercusión real del informe es relativa, dado que se plantea en términos de petición a las autoridades españolas, y, al no formar parte de ninguna directiva europea, no comporta obligación legal de acatamiento. No obstante, representa una llamada de atención que deberá ser tenida en cuenta en el futuro, de cara a la redacción de un nuevo texto sobre costas, ya que la administración española deberá recoger en el futuro estas indicaciones, y, sobre todo, representan un gran

\footnotetext{
${ }^{29}$ Informe Auken, considerando Q.

${ }^{30}$ Informe Auken, considerando $\mathrm{S}$.

31 Informe Auken, petición 4.

32 Informe Auken, petición 16.

33 Informe Auken, petición 22.
} 
deterioro de la imagen de España ante la opinión pública europea. La cuestión no es baladí: el informe termina (petición 35) instando a la Comisión Europea «a que inicie una campaña informativa dirigida a los ciudadanos de la UE que adquieran propiedades inmobiliarias en un Estado miembro que no sea el suyo propio», dejando entrever que en España hay situaciones de indefensión e inseguridad jurídica al adquirir propiedades de uso residencial que pueden estar amenazadas de derribo sin que los compradores sean advertidos de ello. Para una nación que basa el equilibrio de su balanza de pagos en el sector turístico y residencial, este informe puede acarrear una trascendencia inusitada.

\section{LAS REFORMAS DE LA LEY 22/1988, DE COSTAS}

Tras más de veinte años de vigencia, la ley de costas de 1988 parece próxima a una revisión integral, en forma de nuevo texto. Sin embargo, a pesar de las numerosas reclamaciones que se han presentado desde su entrada en vigor, de la complejidad de su puesta en marcha, y de las críticas por parte de quienes la consideran excesiva y por parte de quienes la consideran poco ambiciosa, ningún gobierno -del color político que sea- ha propuesto o insinuado siquiera redactar un nuevo texto.

Esto no quiere decir que el texto actual sea el mismo que el que el Parlamento aprobó en 1988 y se publicó en el Boletín Oficial del Estado el 29 de julio de ese año ${ }^{34}$. A lo largo de estas dos décadas, se han producido algunas modificaciones puntuales de la ley, muchas de ellas de un modo solapado, mediante la incorporación, en otras leyes, de asuntos que competen directamente al espacio costero. Lo más habitual ha sido emplear para ello las leyes de Acompañamiento de los Presupuestos Generales del Estado, cuyo objetivo no debería ser ocultar este tipo de reformas legales, y que, precisamente por ese motivo, fueron derogadas en 2004. De entre las modificaciones más señaladas, merece la pena mencionar las siguientes:

Primera. En octubre de 2002 se presenta, junto con los Presupuestos Generales del Estado 2003, una ley en cuyo artículo 87 se propone una modificación de la ley de costas, suavizando la prohibición de construir en los primeros veinte metros de la servidumbre de protección si «se logra la homogeneización urbanística del tramo de fachada marítima al que pertenecen, o se trate de edificación cerrada, de forma que, tanto las edificaciones existentes como las que puedan ser objeto de autorización, queden adosadas lateralmente a las contiguas». Se permitiría, pues, edificar, siempre que, de este modo, la fachada costera fuera urbanísticamente

${ }^{34}$ La Ley de Costas española puede consultarse en numerosas direcciones de Internet. Entre otras, la propia web del Congreso de los Diputados: http://www.congreso.es/constitucion/ ficheros/leyes_espa/1_022_1988.pdf 
homogénea. La fórmula fue denunciada como una auténtica aberración por Greenpeace y WWF/ADENA (2002) y, tras las elecciones de marzo de 2004, el nuevo gobierno la derogó, al tiempo que se hacía desaparecer esta Ley de Acompañamiento ${ }^{35}$.

Segunda. El 31 de diciembre de 2002, en la misma Ley de Acompañamiento, se limitó el plazo para tramitar y notificar los expedientes de deslinde a un máximo de 24 meses. Esto ha aumentado -si cabe- la complejidad del procedimiento, que ya se ha analizado. La propia Administración de Costas reconoce que «cada vez son más los expedientes de deslinde que son recurridos ante la Audiencia Nacional, aportando los recurrentes estudios técnicos cada vez más complejos con los que cuestionar la bondad de los deslindes aprobados» (MARM, 2009). Este límite de tiempo sigue en vigor.

Tercera. La Ley 13/2003, de 23 de mayo, Reguladora del Contrato de Concesión de Obras Públicas, contempla la posibilidad de que las empresas que realicen una obra -desde una carretera a una regeneración de playas- sufraguen la ejecución de la misma, obteniendo como contraprestación la explotación económica de los resultados. Esto, en el caso del litoral, resulta de una extraordinaria relevancia, puesto que la explotación de los servicios de temporada (normalmente bajo título de autorización administrativa en dominio público, y excepcionalmente como concesiones) recaerían bajo la competencia exclusiva de la empresa que hubiera financiado la regeneración de la playa. Se pueden producir así agravios entre playas cuya regeneración sería muy rentable (por su alta ocupación) y otras donde las empresas no querrían invertir. Los mismos precios a pagar por los usuarios podrían verse afectados, e, indudablemente, podría aumentar la superficie ocupada de la playa por usos recreativos de pago. Hoy en día coexisten en España los dos sistemas: el tradicional, por el cual la administración sufraga el coste de la obra pública y luego ingresa el dinero procedente de los contratos de concesión de los usos en el DPMT, y el sistema derivado de la Ley 13/2003 (llamado sistema alemán). Esta ley incorpora, en su disposición adicional décima, una nueva redacción de los artículos 54 y 84 de la ley 22 /1988, de Costas. El primero de ellos queda así: «podrá otorgarse la autorización para la explotación total o parcial de los servicios de temporada en las playas, como contraprestación al coste de ejecución de una obra pública relacionada con éstas que, por su naturaleza y características, no sea susceptible de explotación económica».

Cuarta. Aunque no constituyó propiamente una modificación de la ley, el 5 de octubre de 2007, la entonces ministra de Medio Ambiente, Cristina Narbona, remitió al Consejo de Ministros la Estrategia para la sostenibilidad en la costa, una «apuesta por el establecimiento de nuevos modos de desarrollo en la franja

\footnotetext{
${ }^{35}$ Diario El País, 5 de septiembre de 2004.
} 
costera, que no estén basados en la ocupación urbanística, sino que se apoyen y potencien el recurso naturalidad del litoral» (ALFONSO, 2007). Lo cierto es que dicha Estrategia, que preveía sistemas participativos de la ciudadanía y constituir una Comisión para la Sostenibilidad de la Costa, falló en lo más importante: no estimaba plazos ni asignaba un presupuesto especial, además de carecer -nuevamente- de una visión de conjunto del espacio litoral nacional. Se basaba, en esencia, en un plan para rescatar concesiones a lo largo de casi $777 \mathrm{kms}$ de la costa mediterránea y de Canarias, con el fin de devolver esos espacios al uso público. La voluntad de la Administración era negociar con los propietarios, no recurrir a la expropiación, pero, para eso, se precisaban dos circunstancias que nunca se concretaron: una asignación presupuestaria de 5.000 millones de euros (recordemos que la Dirección General de Costas nunca ha llegado a los $300 \mathrm{M} €$ de presupuesto) y la necesaria colaboración de las comunidades autónomas, dado que muchas actuaciones se producirían dentro de la servidumbre de protección. Por desgracia, nunca se dotó económicamente esa Estrategia, ni las comunidades autónomas accedieron a participar o cofinanciar el plan. Más desafortunado aún fue el modo con el que la Estrategia se hizo pública ${ }^{36}$, con la difusión de imágenes de demoliciones realizadas en primera línea de costa, que alarmaron a los ocupantes y que contradecían las palabras negociadoras de los responsables del ministerio. No es casualidad que la Plataforma Nacional de Afectados por la Ley de Costas se constituya, precisamente, dos meses después. La anunciada Estrategia no sólo no se cumplió, sino que, seis meses después, el Ministerio de Medio Ambiente desaparece como tal, la ministra dejaría el gobierno y la política costera desarrollada -por el mismo partido políticotras las elecciones de marzo de 2008 será de un signo muy diferente.

Quinta. En efecto, en febrero de 2009, se anuncia la redacción de la Ley General de Navegación Marítima ${ }^{37}$, ley paralela a la de costas, que no debería interferir en el litoral, pero en la que se propone lo que algún medio de comunicación denominó suavización puntual de la ley de $\operatorname{costas}^{38}$. Los propietarios de viviendas en régimen de concesión, hasta entonces incapaces de realizar una venta intervivos, podrán, a partir de este momento, vender la concesión de la misma. No significa recuperar la propiedad, sino tan sólo poder desprenderse de una vivienda que, en muchos casos, genera gastos a los cuales no pueden hacer frente. La realidad, no obstante,

${ }^{36}$ El diario El País publicó, entre el 29 de octubre y el 8 de noviembre de 2007, una serie de reportajes sobre la ocupación de diferentes puntos de la costa española, además de un editorial, el 4 de noviembre, reclamando que «si no se alcanza un acuerdo negociado (...) hay muchas razones para imponerlo por la fuerza de la ley».

${ }^{37}$ En diciembre de 2009 se aprueba el Anteproyecto de la Ley General de Navegacion Marítima, pendiente aún de su sanción definitiva por el Parlamento.

38 Diario El Faro de Vigo, de 3 de febrero de 2009. 
es que la demanda de casas en estas condiciones es muy limitada, pues resulta complicado imaginar a alguien que adquiera una vivienda sabiendo que sólo adquiere el uso temporal de ésta por los años que queden de concesión, y no la propiedad real del inmueble. La modificación, de todos modos, representa un cambio fundamental de actitud, que invalida todas las declaraciones maximalistas anteriores, y coloca, sin duda, a la Administración Central en una posición de debilidad evidente.

Sexta. También, a lo largo de 2009, se han evidenciado ciertos cambios de actitud en la Dirección General de Sostenibilidad de la Costa y del Mar, que ha autorizado a los propietarios de viviendas cuya situación administrativa está pendiente de resolución por los tribunales de justicia y que ocupan -según el deslinde- el dominio público marítimo-terrestre, a realizar obras de mejora de sus viviendas siempre que no impliquen aumento de volumen ni ocupación de una superficie mayor. No se trata realmente de una modificación legal (no aparece recogida en texto alguno), sino de una diferente interpretación del artículo 6 de la ley: mientras que antes la Administración denegaba sistemáticamente estos permisos, en un intento de aumentar la tensión con los inquilinos y forzar así el rescate anticipado de la concesión, ahora se consiente este refuerzo (sustitución de ventanas, barandillas oxidadas, mejoras estéticas, reparación de desconchados, pintado de fachadas), atendiendo a la seguridad de los ocupantes y de los transeúntes. Se pueden argumentar diferentes razones para explicar este cambio de actitud del gobierno, siendo una de ellas el cambio de responsables al frente del Ministerio de Medio Ambiente ${ }^{39}$ y, desde luego, las consecuencias de la difusión del informe de Auken.

Séptima. En el ejercicio de sus competencias en materia de ordenación territorial y del litoral, algunas comunidades autónomas han redactado normas que condicionan la puesta en marcha de determinados aspectos de la ley de costas. Claro está que una ley de ámbito autonómico no puede suplantar a otra estatal, pero sí puede perturbar su aplicación y generar conflictos competenciales, aunque sea complementaria a la norma general, si ofrece una diferente interpretación del territorio. Esto ha ocurrido de modo particularmente claro en Galicia, donde la Ley de Vivienda de diciembre de 2008 permitió proteger cientos de viviendas situadas en primera línea de costa, y en Canarias, donde se ha aprobado, en marzo de 2009, una norma similar, que alude al valor etnográfico de los poblados marítimos de primera línea, como respuesta política a la fortísima reacción social que tuvo lugar tras el derribo del poblado de Cho Vito, al que se hizo referencia páginas atrás.

${ }^{39}$ El 14 de abril de 2008 Elena Espinosa sustituye a Cristina Narbona al frente del Ministerio de Medio Ambiente (que recibe las competencias de Agricultura y pasa a denominarse de Medio Ambiente y Medio Rural y Marino). La anterior ministra había hecho de la recuperación de la costa como espacio público uno de sus ejes de actuación principal. 


\section{BALANCE FINAL}

Transcurridos más de cuarenta años desde la aprobación de la primera ley de costas, puede afirmarse que España carece de una verdadera política coherente sobre su litoral. Si el texto de 1969 contemplaba la presencia de propiedad privada inserta en el dominio público marítimo-terrestre, la ley posterior, de 1988, es un texto que llega tarde, que consiente los colosales cambios en la ordenación municipal ocurridos durante su tramitación parlamentaria, que emplea maneras expeditivas con los ocupantes de las primeras líneas que habían adquirido legítimamente su propiedad y que, sin embargo, no establece responsabilidad alguna por parte de las administraciones (municipales, autonómicas y central) que consintieron, ampararon y promovieron esa ocupación masiva e indiscriminada del litoral. Ha cumplido, eso sí, una «función educativa» (SANZ LARRUGA, 2008), al contribuir a la difusión de los valores ambientales del litoral en la sociedad, pero, desgraciadamente, no ha logrado sus ambiciosos propósitos.

Paradójicamente, a pesar de su aparente fuerza inicial, a lo largo de los años de vigencia de la ley, la situación de las costas españolas no sólo no ha mejorado, sino que es notablemente peor. Entre mediados de 2006 y mitad de 2007, antes de que se produjera la crisis del sector inmobiliario, se autorizó en España la construcción de tres millones de nuevas viviendas en el litoral (LÓPEZ DE URALDE, 2007), una cifra disparatada en una costa que sigue sin estar plenamente deslindada, a cuya gestión se asigna la mitad del dinero del que mueve anualmente una universidad mediana y para la que se carece, como vemos, de una coherencia política clara.

Ayudaría, sin duda, en este sentido, la constitución en España de un órgano gestor integrado del litoral, que actuara de manera coordinada -pero desde un nivel superior- con las comunidades autónomas, y no condicionado por ellas. Si para eso es preciso cambiar la ley de costas, deberán ser los juristas quienes redacten el nuevo texto y son los dos principales partidos con opciones de gobierno nacional los que tiene la obligación de alcanzar un acuerdo de estado sobre el modelo de litoral que desean para España, con el fin de que la política estatal de costas no esté determinada por demandas autonómicas ${ }^{40}$. En cualquier caso, debería contemplarse la necesidad de constituir un órgano central, más al estilo del Conservatoire du Littoral francés que del National Trust británico, que pudiera

${ }^{40}$ La petición, por ejemplo, del Partido Nacionalista Vasco de ampliar las aguas interiores -de gestión autonómica- desplazando hacia el exterior las líneas de base, y, por tanto, a costa del Mar Territorial -de gestión central-, se ha producido siempre coincidiendo con las legislaturas en las que sus escaños eran determinantes en la gobernabilidad estatal. Ver, entre otros, Diario de Sesiones del Senado, de 20 de abril de 1998. 
rescatar del tráfico mercantil determinados enclaves de la costa, no sólo con el fin de preservarlos, sino de potenciar sus valores y su adecuada inserción en redes de espacios naturales protegidos que sean algo más que un salpicado de puntos inconexos en los mapas del Ministerio de Medio Ambiente, Rural y Marino ${ }^{41}$.

De igual modo, es urgente evitar la dispersión administrativa horizontal. Ya desde su aprobación, la ley recibió críticas porque «en lugar de avanzar en el proceso de integración (...) se intenta consolidar un modelo administrativo con tres niveles de decisión» (OLMOS, 1988). Pero no se trata sólo de que el litoral sea un espacio donde concurren las competencias de tres administraciones, sino que, además, la gestión está fragmentada entre diferentes ministerios o consejerías/consellerias de una misma administración. Así, desde la aprobación de la Constitución Española (1978) y de los primeros Estatutos de Autonomía (poco después, en la década del ochenta), las competencias en materia de ordenación del territorio y del litoral recaen en las Comunidades Autónomas, así como la gestión de los puertos deportivos. Por lo tanto, las directrices básicas se establecen a nivel estatal, sobre todo en lo que respecta a los bienes de dominio público marítimo terrestre -de soberanía estatal y uso público-, pero la normativa sobre el resto del espacio litoral y su desarrollo corresponde a los gobiernos regionales. Incluso dentro de ellos se mantiene, en muchas ocasiones, la separación entre las áreas costeras (muchas veces dentro de los departamentos de medio ambiente o territorio) y portuarias, por lo general vinculadas a los departamentos de transporte. Que existiera una consejería/conselleria de litoral, específica sobre este ámbito, y cuyo fin fuera la ordenación de los distintos usos y actividades que se dan cita en este espacio, así como colaborar con la administración central en las tareas pendientes: culminación del deslinde, rescate de concesiones, negociación justa y equitativa con los propietarios, liberación de espacios de primeras líneas para revertirlos al uso público, planificación de playas, etc. Aunque requiere de una extraordinaria -y utópica- concertación política a todos los niveles, sin duda esta medida contribuiría a que las costas españolas recuperasen el tiempo perdido. Al menos parte de los últimos cuarenta años.

\section{BIBLIOGRAFÍA}

Alfonso, C. (2007): «Estrategia para la sostenibilidad de la costa. Nuevo modelo de gestión de la franja costera», Ambienta. Revista del Ministerio de Medio Ambiente, $\mathrm{n}^{\mathrm{o}} 71$ (noviembre 2007), pp. 20-24.

\footnotetext{
${ }^{41}$ Algunos especialistas han empleado, incluso, términos tan expresivos como el de planeamiento mosaico para referirse al tratamiento aislado e inconexo entre los documentos de planeamiento de municipios limítrofes (BLASCO, 2004).
} 
Auken (2009): Resolución del Parlamento Europeo, de 26 de marzo de 2009, sobre el impacto de la urbanización extensiva en España en los derechos individuales de los ciudadanos europeos, el medio ambiente y la aplicación del Derecho comunitario, con fundamento en determinadas peticiones recibidas (2008/2248(INI). Puede consultarse la versión española del informe en la dirección abreviada: http://tinyurl.com/ycn2pns.

Barragán Muñoz, J. M. (1994): Ordenación, planificación y gestión del espacio litoral. Ed. Oikos Tau. Barcelona, 298 p.

Blasco Esteve, A. (2004): «Planificación y gestión del territorio turístico de las Islas Baleares», en Melgosa, F. J. (ed.): Derecho y turismo, Ediciones de la Universidad de Salamanca, pp. 385-436.

GreEnPEace y WWF/Adena (2002): Análisis del proyecto de ley de medidas fiscales y del orden social, en la modificación de la ley 22/1988, de Costas. Noviembre 2002, 45 pp. URL: http://www.greenpeace.org/raw/content/espana/reports/ modificaci-n-de-la-ley-de-cost.pdf

López de URAlde, J. (2007): «Recuperemos la costa», El Mundo, 28 de junio de 2007. http://www.elmundo.es/elmundo/2007/06/28/ecologia/1183017826.html

M.A.R.M. (2009): «Plan de deslindes. El deslinde del dominio público marítimo-terrestre». Documento informativo del Ministerio de Medio Ambiente y Medio Rural y Marino, en http://www.mma.es/secciones/acm/aguas_marinas_litoral/gdpmt/pdf/plan_deslindes_jun09.pdf [consultado el 10 de diciembre de 2009].

M.E.H. (2009): Presupuestos Generales del Estado para 2009. Ministerio de Economía y Hacienda. http://www.sgpg.pap.meh.es/Presup/PGE2009Proyecto/ MaestroDocumentos/PGE-ROM/doc/1/4/20/2/N_09_A_R_31_123_1_1_7. PDF [consultado el 10 de diciembre de 2009]. También: http://www.sgpg. pap.meh.es/Presup/PGE2009Proyecto/MaestroDocumentos/PGE-ROM/ Cuerpo.htm.

M.M.A. (2005): «El deslinde del dominio público marítimo-terrestre», Ambienta. Revista del Ministerio de Medio Ambiente, no 47, septiembre 2005, pp. 16-20.

Olmos, J. (1988): «Ley de costas: balance y perspectivas de un proceso», El País, 17 de diciembre de 1998.

Sanz Larruga, J. (2008): «La ley de costas, veinte años después», Boletín costero, $n^{\circ} 4$. Boletín de la Gestión Costera de la Provincia de Cádiz. Número extraordinario titulado Veinte años de la ley de costas. Octubre 2008.

Torres Alfosea, F. J. (1997): Ordenación del litoral en la Costa Blanca. Servicio de Publicaciones de la Universidad de Alicante, Alicante, 296 p.

Torres Alfosea, F. J. (2009): «La ocupación del dominio público marítimo-terrestre en España», Investigaciones Geográficas n 50, Instituto Universitario de Geografía. Universidad de Alicante. 